$\begin{array}{r}\text { JURNAL } \\ \begin{array}{r}\text { EKONOMI PERTANIAN, SUMBERDAYA DAN LINGKUNGAN } \\ \text { (Journal of Agriculture, Resource, and Enviromental Economics) }\end{array} \\ \hline \text { JAREE }\end{array}$

\title{
Hubungan Ekspor-Impor Produk Domestik Bruto (PDB) di Sektor Pertanian Indonesia
}

Fitria Dewi Raswatie ${ }^{1)}$

\section{INFO NASKAH : \\ Proses Naskah: \\ Diterima 21 Februari 2014 \\ Diterima hasil revisi 17Maret 2014 \\ Diterima untuk terbit 11 April 2014 \\ Terbit April 2014}

Keywords :

Agricultural Export

Chow Test

ECM

Agricultural GDP

TFP.

\begin{abstract}
The agricultural sector has an important role in developing economy as a contribution for the national Gross Domestic Product (GDP). Thus, it iimportant to see agricultural export related to agricultural GDP. Structural change caused by economic crisis is also important to be observed in terms of its influence toward variables in the agricultural sector. This research functions to: (1) Analyze short term and long term relations between agricultural export and GDP of the agricultural sector and other variables in Indonesia's
\end{abstract}

agricultural sector; (2) Analyze structural in Indonesia's agricultural sector. The method used is ECM model and Chow Test. Agricultural GDP has a different relation towards agricultural export in short term and long term. Then, there was a structural change caused by economic crisis in 1997. Estimation result after added by monetary crisis dummy in 1997 shows that in short term, agricultural GDP one year previously, agricultural TFP, agricultural domestic price, agricultural export price, agricultural domestic price one year previously, and economic crisis dummy of 1997 have significant influences toward agricultural export. Analysis of the new ECM result (short term) showst that the parameter coefficient signs of the following variables: agricultural GDP, agricultural TFP, agricultural domestic price, agricultural export price, in accordance with the hypothesis are variables with a one year lag. There is a lag of agricultural export in response to the influencing variables.

\section{PENDAHULUAN}

Sektor pertanian memiliki peranan penting dalam pertumbuhan ekonomi Indonesia dengan menyediakan kebutuhan pangan masyarakat secara langsung, memberi kontribusi dalam pembentukan Produk Domestik Bruto (PDB) nasional, menyerap tenaga kerja, menghasilkan devisa negara, dan berfungsi dalam mengendalikan inflasi. Sektor pertanian tahun 2011, misalnya, memberikan kontribusi sebesar Rp.313,73 triliun terhadap pembentukan PDB nasional di mana nilai tersebut lebih besar dibandingkan tahun 2010 yang mencapai Rp. 304,74 triliun. Tahun 2011 pertumbuhan PDB sektor pertanian mencapai 2,95 persen dibandingkan tahun sebelumnya. Pertumbuhan sektor pertanian berasal dari pertumbuhan terbesar yang dicapai subsektor perikanan sebesar 6,72 persen atau sebesar Rp 54.064,30 miliar pada tahun 2011. Kemudian disusul oleh subsektor peternakan yang

Fitria Dewi Raswatie

Departemen Ekonomi Sumberdaya dan Lingkungan, Institut Pertanian Bogor e-mail: dewiraswatie@gmail.com 
mengalami pertumbuhan sebesar 4,49 persen atau sebesar $\mathrm{Rp} \mathrm{39.929,2} \mathrm{miliar} \mathrm{pada} \mathrm{tahun}$ 2011.Kontribusi sektor pertanian terhadap PDB nasional menduduki peringkat ketiga setelah sektor industri pengolahan kemudian sektor perdagangan, hotel, dan restoran. Sektor pertanian memberikan kontribusi sebesar 12,74 persen terhadap PDB nasional. Kontribusi terbesar terhadap PDB nasional berasal dari sektor industri pengolahan diikuti oleh sektor perdagangan, hotel, dan restoran yang masing-masing memberikan kontribusi sebesar 25,67 persen dan 17,75persen.

Peran sektor pertanian juga dapat dilihat dari kemampuan menyerap tenaga kerja. Tenaga kerja sektor pertanian tahun 2010 dan 2011 berturut-turut sebesar 41,50 juta dan 39,33 juta orang (CEIC2012d). Sektor pertanian merupakan sektor yang mampu menyerap tenaga kerja terbesar, kemudian diikuti oleh sektor perdagangan dan sektor jasa-jasa. Tahun 2011, sektor pertanian mampu menyerap 35,86 persen tenaga kerja yang kemudian disusul oleh sektor perdagangan dan sektor jasa-jasa sebesar 21,33 persen dan 15,18 persen dari jumlah tenaga kerja berdasarkan lapangan usaha.

Peran sektor pertanian dalam pembentukan devisa negara ditunjukkan dengan nilai neraca perdagangan yang positif meskipun dengan laju pertumbuhan neraca perdagangan yang berfluktuasi. Neraca perdagangan sektor pertanian berfluktuasi karena peningkatan nilai ekspor diikuti oleh perkembangan nilai impor yang berfluktuasi. Nilai ekspor pertanian sebagai penyumbang devisa pada tahun 2010 sebesar US\$32.519 juta. Nilai ini meningkat sebesar 41,16 persen dari tahun 2009.Sedangkan nilai impor pertanian tahun 2010 sebesar US \$ 16.874 juta. Nilai impor pertanian mengalami peningkatan sebesar 41,27 persen dari tahun 2009. Kondisi perdagangan sektor pertanian disajikan pada Tabel 1 .

Kondisi perdagangan di sektor pertanian menunjukkan bahwa perekonomian Indonesia semakin terbuka dan aktivitas perdagangan luar negeri melalui kegiatan impor dan ekspor semakin meningkat. Peningkatan ekspor pertanian menunjukkan pendapatan penduduk Indonesia semakin tergantung dari hasil penjualan barang produksi domestik di luar negeri atau dengan kata lain pendapatan penduduk Indonesia semakin tergantung dari kondisi ekonomi negara-negara pengimpor. Sedangkan peningkatan impor pertanian menunjukkan bahwa ekonomi Indonesia semakin tergantung dari barang-barang yang dihasilkan oleh negara-negara lain. Dengan demikian, pertumbuhan ekonomi Indonesia semakin tergantung dengan aktivitas perdagangan luar negeri.

Tabel 1 Nilai ekspor dan impor sektor pertanian Indonesia (ribu US \$) tahun 2008 - 2010

\begin{tabular}{lccc}
\hline & \multicolumn{3}{c}{ Tahun } \\
\cline { 2 - 4 } & 2008 & 2009 & 2010 \\
\hline Ekspor & 29.300 .336 & 23.037 .582 & 32.519 .850 \\
Impor & 11.341 .138 & 9.897 .316 & 13.982 .414 \\
Neraca & 17.959 .198 & 13.140 .266 & 18.537 .436 \\
\hline
\end{tabular}

Sumber: CEIC (2012e), diolah.

Peningkatan ekspor secara teori akan berpengaruh terhadap peningkatan PDB pertanian. Akan tetapi, apakah benar ekspor pertanian berkontribusi dalam peningkatan PDB pertanian dan sebaliknya, apakah PDB pertanian juga mampu memberikan kontribusi terhadap perkembangan ekspor perlu dilakukan analisis mendalam mengenai hal tersebut. Dengan kata lain, perlu dilakukan analisis terhadap kedua variabel tersebut agar dapat melihat bagaimana hubungan ekspor pertanian dengan PDB pertanian.

Pergerakan variabel ekspor pertanian dan PDB pertanian selama periode tahun 20072011 cukup fluktuatif. Hal ini menunjukkan ketika salah satu variabel berubah maka tidak langsung diikuti oleh perubahan variabel yang lain. Dampak perubahan PDB pertanian akibat perubahan ekspor diduga terjadi setelah beberapa periode waktu (lag) dan juga diakibatkan karena perubahan variabel ekonomi selain ekspor pertanian. Dengan demikian, penting untuk dilakukan analisis untuk melihat hubungan antara ekspor pertanian dan PDB pertanian dalam kerangka pertumbuhan ekonomi. Sektor pertanian Indonesia mengalami 
perubahan struktur (structural change) pada tahun 1997 yang dipicu karena adanya krisis ekonomi yang berawal dari resesi global di Amerika Serikat. Dengan demikian, perlu dilakukan analisis adanya perubahan struktur (structural change) di sektor pertanian Indonesia.

Ekspor Pertanian (Juta US\$)

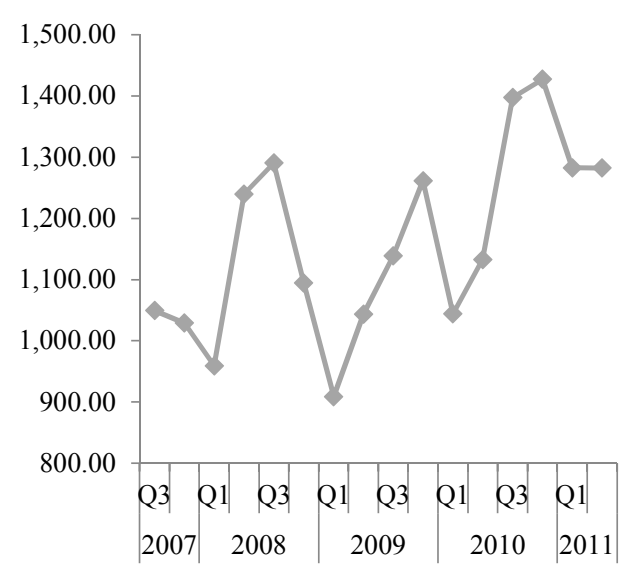

PDB Pertanian (Miliar Rp)

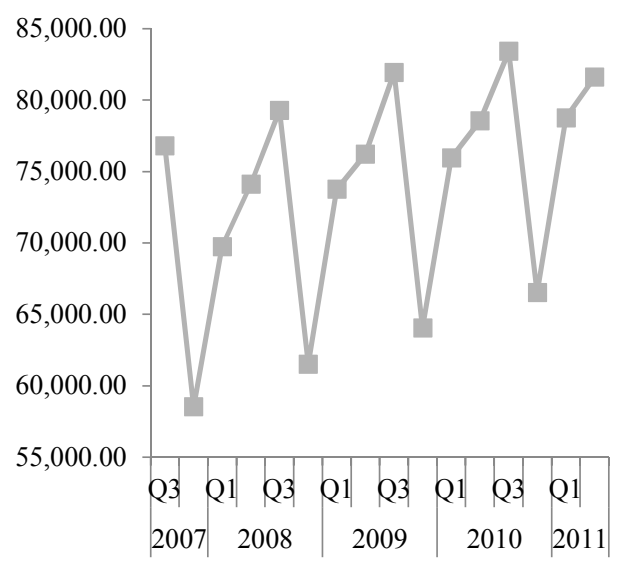

Sumber : CEIC (2012a, 2012e), diolah

Gambar 1 Perkembangan nilai ekspor pertanian dan PDB pertanian tahun 2007-2011

\section{METODE PENELITIAN}

\section{Jenis Data}

Jenis data yang digunakan dalam penelitian ini adalah data sekunder berupa data time series periode 1980 sampai dengan 2011. Data yang digunakan terdiri dari data PDB nasional, PDB pertanian, tenaga kerja di sektor pertanian, investasi penanaman modal asing dan penanaman modal dalam negeri di sektor pertanian, volume ekspor total, volume ekspor pertanian, nilai ekspor pertanian, harga domestik pertanian, harga ekspor pertanian dan nilai tukar.

\section{Analisis Hubungan Ekspor Pertanian-PDB Pertanian Indonesia}

Model Error Correction Model (ECM) digunakan untuk melihat hubungan jangka pendek dan jangka panjang antara ekspor pertanian dengan PDB pertanian serta variabelvariabel lain yang mempengaruhi ekspor pertanian. Estimasi jangka panjang dilakukan dengan menggunakan uji kointegrasi Engel-Granger. Sedangkan estimasi jangka pendek dengan menggunakan ECM atau model koreksi kesalahan. Syarat yang harus dipenuhi dalam menggunakan ECM adalah terdapat minimal satu variabel yang tidak stasioner. Jika seluruh data yang digunakan ternyata stasioner, maka persamaan tersebut tidak dapat dianalisa dengan menggunakan ECM.

\section{Pengujian Pra Estimasi \\ - Uji Stasioneritas Data}

Pengujian stasioneritas data dilakukan dengan menguji akar-akar unit atau unit root test. Data yang tidak stasioner akan mempunyai akar-akar unit, sebaliknya data yang stasioner tidak mempunyai akar-akar unit. Data yang tidak stasioner akan menghasilkan spurious regression yaitu regresi yang menggambarkan hubungan dua variabel atau lebih yang terlihat signifikan secara statistik tetapi pada kenyataanya tidak atau tidak sebesar regresi yang dihasilkan tesebut. 
Model pengujian unit root yang digunakan dalam banyak penelitian adalah model Aughmented Dickey Fuller (ADF) test. Model umum dari uji ADF adalah sebagai berikut:

$$
\Delta \mathrm{y}_{\mathrm{t}}=\mathrm{k}+\alpha \mathrm{y}_{\mathrm{t}-1}+\mathrm{c}_{1} \Delta \mathrm{y}_{\mathrm{t}-1}+\mathrm{c}_{2} \Delta \mathrm{y}_{\mathrm{t}-2}+\ldots . .+\mathrm{c}_{\mathrm{p}} \Delta \mathrm{y}_{\mathrm{t}-\mathrm{p}}+\text { Trend }+\varepsilon_{\mathrm{t}} \ldots \ldots \ldots \ldots(1)
$$

Hipotesis yang diuji pada uji ADF adalah apakah $\mathrm{H}_{0}:: \delta=0$ dengan hipotesis alternatif $\mathrm{H}_{0}$ : $\delta<0$. Jika nilai uji ADF statistiknya lebih besar dari Mac Kinnon Critical Value maka hipotesis nol yang menyatakan bahwa data tidak stasioner ditolak terhadap hipotesis alternatifnya dengan kata lain dengan menolak $\mathrm{H}_{0}$ berarti data stasioner. Solusi yang dapat dilakukan apabila data tidak stasioner pada uji ADF adalah dengan melakukan difference non stasionary processes.

\section{- Uji Kointegrasi (Cointegration)}

Uji kointegrasi dilakukan untuk melihat hubungan jangka panjang antar variabel. Metode yang dapat digunakan untuk melakukan uji kointegrasi, diantaranya Engle-Granger Cointegration Test, dan Cointegration Regression Durbin-Watson Test. Metode EngleGranger Cointegration Testdilakukan dengan menggunakan metode Augmented DickeyFuller (ADF) dalam dua tahap. Tahap pertama, variabel-variabel (dalam level) diuji secara sendiri-sendiri dengan metode ADF, dan umumnya akan diperoleh variabel-variabel yang tidak stasioner. Tahap dua, variabel dependen diregresi dengan variabel-variabel penjelas dan kemudian lakukan pengujian terhadap residual regresi tersebut. Oleh karena itu, metode ini juga disebut juga sebagai Augmented Engle-Granger (AEG) dengan cara:

$$
\Delta u_{t}=\alpha_{1} u_{t-1}+\sum_{j=1}^{\rho} c_{j} \Delta u_{t-\rho}+e_{t}
$$

di mana: $u_{i}$ adalah residual, $\rho$ adalah lag optimal dari variabel dependen, dan $\mathrm{e}_{\mathrm{t}}$ adalah error term. Kemudian hasil t-ADF dibandingkan dengan nilai-nilai kritis MacKinnon untuk menguji hipotesis Ho: tidak terkointegrasi dan $\mathrm{H}_{1}$ : terkointegrasi.

Jika Ho ditolak maka variabel $u_{i}$ adalah stasioner atau dalam hal ini kombinasi linear antar variabel adalah stasioner.Artinya meskipun variabel-variabel yang digunakan tidak stasioner, namun dalam jangka panjang variabel-variabel tersebut cenderung menuju pada keseimbangan.Oleh karena itu, kombinasi linear dari variabel-variabel tersebut disebut regresi kointegrasi. Parameter-parameter yang dihasilkan dari kombinasi tersebut dapat disebut sebagai koefisien-koefisien jangka panjang atau co-integrated parameters.

Secara umum, persamaan jangka panjang didefinisikan sebagai berikut :

$$
Y=C+a_{1} X_{1 t}+a_{2} X_{2 t}+a_{3} X_{3 t}+\ldots+a_{5} X_{n t}
$$
logaritma):

Sedangkan persamaan jangka panjang yang diestimasi dalam penelitian sebagai berikut (dalam

\begin{tabular}{|c|c|}
\hline$a_{0}$ & $=$ intersep \\
\hline$a_{n}$ & $\begin{array}{l}=\text { parameter yang diduga, dimana } n=1,2, . .5 \text { dan menggambarkan hubungan } \\
\text { jangka panjang antar variabel independent dengan variabel dependent. }\end{array}$ \\
\hline $\log X_{t}$ & $=$ Nilai ekspor pertanian pada periode $\mathrm{t}$ (juta US\$) \\
\hline $\operatorname{LogPDB}_{t}$ & $=$ PDB sektor pertanian pada periode $\mathrm{t}($ Miliar Rp) \\
\hline $\operatorname{LogTFP}_{t}$ & $\begin{aligned}= & \text { Total Factor Productivity (TFP) sektor pertanian pada } \\
& \text { periode t. }\end{aligned}$ \\
\hline $\operatorname{LogPX}_{t}$ & $=$ Harga ekspor sektor pertanian pada periode $\mathrm{t}$ (Indeks) \\
\hline $\operatorname{LogPD}_{t}$ & $=$ Harga domestik sektor pertanian pada periode $\mathrm{t}($ Indeks $)$ \\
\hline $\operatorname{LogER}_{t}$ & $=$ Nilai Tukar pada periode $\mathrm{t}(\mathrm{Rp} / \mathrm{US} \$)$ \\
\hline
\end{tabular}

$$
\begin{aligned}
& \log X t=a_{0}+a_{1} \log P D B_{t}+a_{2} \log T F P_{t}+a_{3} \log P D_{t}+a_{4} \log P X_{t}+a_{5} \log E R_{t}+ \\
& e_{t} \ldots \ldots \ldots \ldots \ldots \ldots \ldots \ldots \ldots \ldots \ldots \ldots \ldots \ldots \ldots \ldots \ldots \ldots \ldots \ldots . . .(4)
\end{aligned}
$$

dimana : 
$\mathrm{e}_{\mathrm{t}} \quad=$ Error distribunce pada periode $\mathrm{t}$

\section{- Estimasi Error Correction Model (ECM)}

Penggunaan ECM bertujuan untuk mengatasi masalah adanya perbedaan kekonsistenan hasil antara analisis dalam jangka pendek dan jangka panjang dengan cara proporsi disequilibrium pada satu periode, dikoreksi pada periode berikutnya sehingga tidak ada informasi yang dihilangkan hingga penggunaan untuk analisis jangka panjang (Thomas, 1997). Karena kelebihannya dalam menggabungkan efek jangka pendek dan jangka panjang, ECM menjadi model yang dapat menjelaskan variabel dengan baik. Model ECM terbentuk dari fungsi awal sebagai berikut :

$$
\mathrm{Y}=\mathrm{f}\left(\mathrm{X}_{1}, \mathrm{X}_{2}, \mathrm{X}_{3}\right) \text {..... }
$$

dengan model linier dapat ditulis sebagai berikut :

$\mathrm{Y}=\boldsymbol{b}_{0}+b_{1} X_{1}+b_{2} X_{2}+b_{3} X_{3}+u$

kemudian model (3.11) dibentuk menjadi model dinamis yang menyertakan kelambanan atau lag yang biasa dikenal dengan Error Correction Model yang didefinisikan sebagai berikut :

$D Y=b_{0}+b_{1} D X_{1}+b_{2} D X_{2}+b_{3} D X_{3}+b_{4} B X_{1}+b_{5} B X_{2}+b 6 B X_{3}+$ dimana :

$D \quad=$ First Difference

$B=$ Kelambanan kebelakang (backward lag operator)

Model persamaan (3.12) dapat dinyatakan sebagai berikut :

$$
D Y t=b_{0}+b_{1} D X_{1 t}+b_{2} D X_{2} t+b_{3} D X_{3} t+b_{4} X_{1 t-1}+b_{5} X_{2 t-1}+b 6 X_{3 t-1}+
$$

Bentuk umum dari persamaan ECM jangka pendek sebagai berikut :

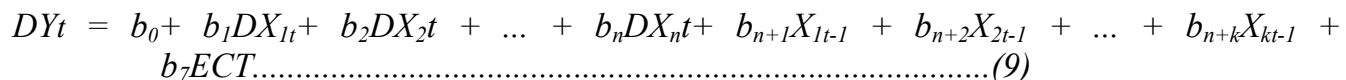

Persamaan ECM dalam penelitian sebagai berikut (dalam logaritma) :

$D \log X t=b_{0}+b_{1} D \log P D B t+b_{2} D \log T F P_{t}+b_{3} D \log P D t+b_{4} D \log P X t+b_{5} D \log E R_{t}+b_{6}$ $D \operatorname{LogXt-1}+b_{7} D \log P D B t-1+b_{8} D \log T F P_{t-1}+b_{9} D \log P D t-1+b_{10} D \log P X t-1+$ $b_{11} D \log E R_{t}-1+b_{12} E C T \ldots \ldots \ldots \ldots \ldots \ldots \ldots \ldots \ldots \ldots \ldots \ldots \ldots \ldots \ldots \ldots \ldots \ldots \ldots \ldots . .(10)$

dengan $b_{1}>0, b_{2}>0, b_{3}<0, b_{4}>0, b_{5}>0, b_{6}>0, b_{7}>0, b_{8}>0, b_{9}<0, b_{10}>0, b_{11}>0$ dan $-1<b_{12}<0$.

dimana :

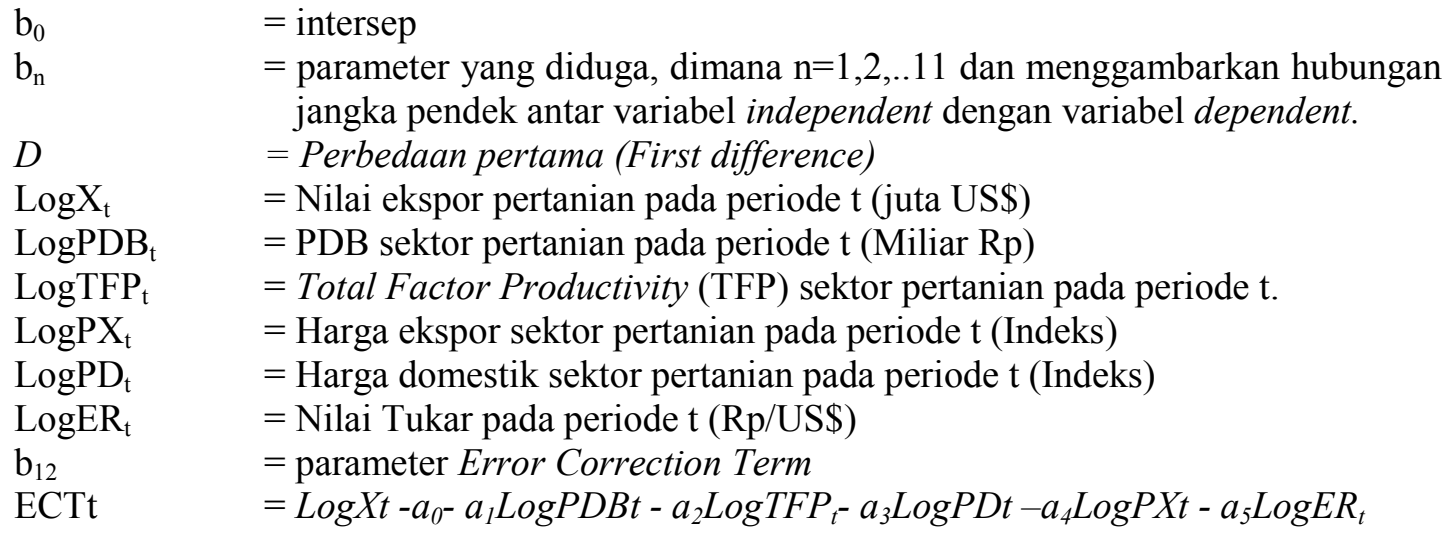

Untuk mengetahui kebaikan dari model ECM, maka dilakukan uji kebaikan model ECM untuk mengetahui ada tidaknya pelanggaran asumsi regresi yang muncul pada estimasi model jangka pendek eskpor pertanian dengan PDB pertanian dan variabel lain yang mempengaruhi ekspor pertanian. Uji kebaikan model ECM yang digunakan dalam penelitian berupa pengujian pelanggaran asumsi klasik yang terdiri dari uji heteroskedastisitas, uji autokorelasi, uji normalitas dan uji multikolinearitas. 


\section{Analisis Perubahan Struktur (Structural Change) di Sektor Pertanian}

Untuk mengetahui ada atau tidak perubahan struktur (structural change) pada model ECM yang telah diketahui, maka dilakukan uji stabilitas pada parameternya dengan menggunakan uji break point Chow. Diduga terdapat potensi ketidakstabilan parameter selama terjadi krisis ekonomi pada tahun 1997, dimana efek dari variabel-variabel yang ada dapat berubah dan menyebabkan berubahnya signifikansi pengaruh dari variabel-variabel yang terdapat dalam penelitian. Dengan demikian, akan dilakukan uji break point Chow untuk menganalisis konsistensi parameter sebelum dan sesudah terjadinya krisis ekonomi tahun 1997. Apabila hasil uji Chow menunjukkan terdapat structural break pada tahun 1997, maka break date tersebut dimasukkan ke dalam model ECM sebagai variabel dummy. Persamaan ECM menjadi sebagai berikut (dalam logaritma) :

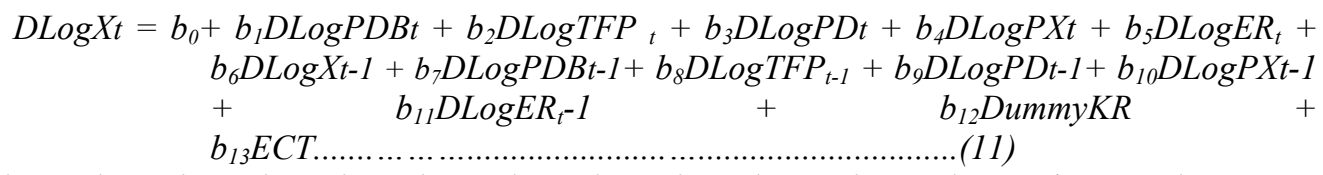

dengan $b_{1}>0, b_{2}>0, b_{3}<0, b_{4}>0, b_{5}>0, b_{6}>0, b_{7}>0, b_{8}>0, b_{9}<0, b_{10}>0, b_{11}>0, b_{12}>0$, dan $-1<b_{13}<0$.

dimana :

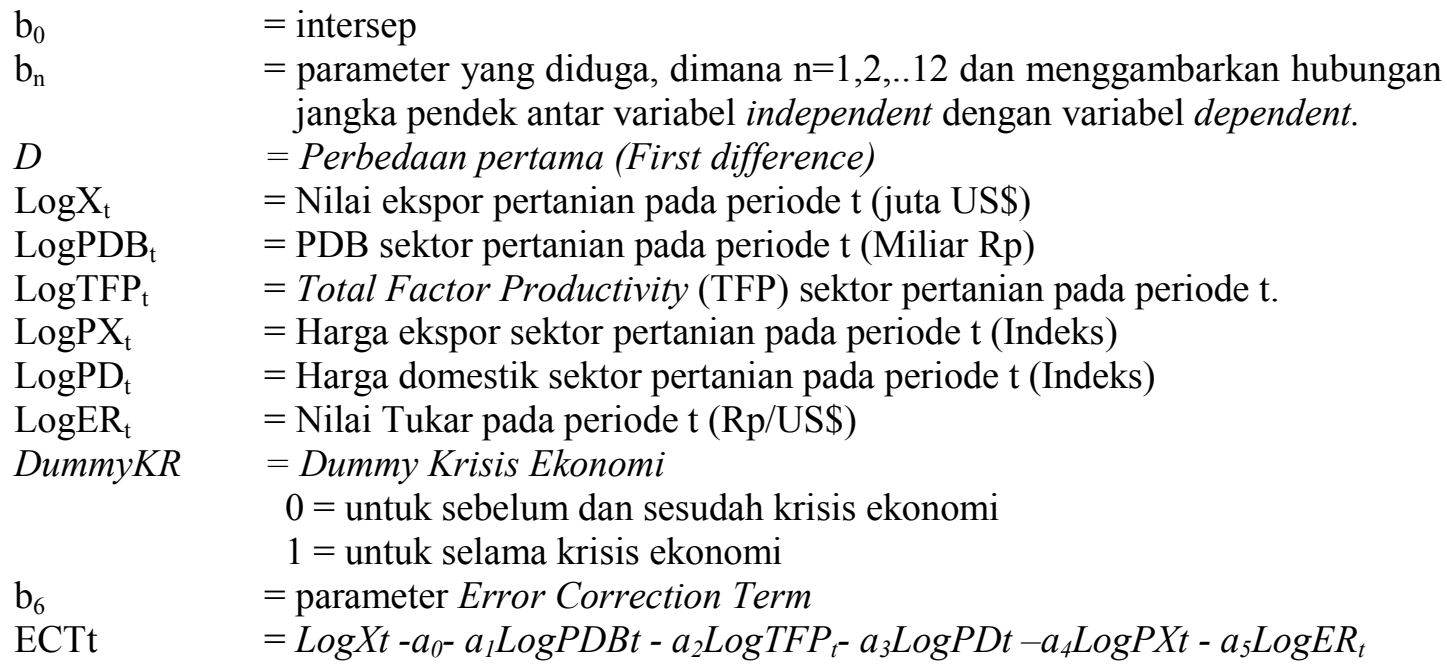

\section{HASIL DAN PEMBAHASAN}

\section{Hubungan Ekspor Pertanian - PDB Pertanian di Indonesia Uji Stasioneritas Data}

Uji kestasioneritasan dalam model didasarkan pada uji Augmented Dickey Fuller (ADF), di mana pengujian ini melihat ada atau tidaknya unit root dalam variabel pada tingkat level dan first difference. Berdasarkan hasil Tabel 2 dapat dilihat bahwa hampir semua data

Tabel 2 Hasil pengujian akar unit pada tingkat level dan 1st different

\begin{tabular}{ccccc}
\hline \multirow{2}{*}{ Variabel } & \multicolumn{4}{c}{ ADF Test Statistic } \\
\cline { 2 - 5 } & $($ Level $)$ & Prob & (1st Diff) & Prob \\
\hline LOGX & -4.331892 & 0.0089 & -12.16967 & 0.0000 \\
LOGPDB & -2.076215 & 0.5382 & -4.422474 & 0.0074 \\
LOGTFP & -5.728229 & 0.0003 & -5.184403 & 0.0013 \\
LOGPX & -4.266083 & 0.0104 & -11.58136 & 0.0000 \\
LOGPD & -2.505743 & 0.3232 & -3.602392 & 0.0466 \\
LOGER & -1.175236 & 0.8983 & -4.793379 & 0.0031 \\
\hline
\end{tabular}

Sumber : Data primer, diolah (2013)

Keterangan : cetak miring menunjukkan stasioner pada tingkat kepercayaan 5 persen. 
yaitu PDB pertanian, harga domestik pertanian, dan nilai tukar (exchange rate) tidak stasioner pada tingkat level karena nilai ADF ketiga variabel tersebut lebih besar dari nilai kritis MacKinnon pada taraf nyata 5 persen. Keadaan ini menunjukkan bahwa model yang digunakan memenuhi syarat untuk diestimasi dengan menggunakan metode ECM, karena minimal ada satu variabel yang tidak stasioner pada level. Berdasarkan hasil uji stationeritas variabel pada tingkat level, maka perlu dilanjutkan dengan uji akar unit pada first difference. Uji ini dilakukan sebagai konsekuensi dari tidak terpenuhinya asumsi stasioneritas pada derajat nol atau $\mathrm{I}(0)$. Hasil uji akar unit tingkat derajat terintegrasi satu I(1) atau first difference menunjukkan semua data bersifat stasioner, hal tersebut dikarenakan nilai ADFnya lebih kecil daripada nilai kritis MacKinnon pada taraf nyata 5 persen.

\section{Uji Kointegrasi}

Uji kointegrasi merupakan salah satu bentuk uji dalam model dinamis, dimana tujuan dari uji tersebut adalah untuk mengetahui ada tidaknya hubungan jangka panjang diantara variabel-variabel yang diamati.Variabel-variabel dikatakan saling terkointegrasi jika ada kombinasi linier diantara variabel-variabel yang tidak stasioner dan residual dari kombinasi linier tersebut harus stasioner.Uji kointegrasi Engel-Granger digunakan untuk mengestimasi hubungan jangka panjang antara ekspor pertanian (LogX) dengan PDB pertanian (LogPDB) serta variabel lain yang mempengaruhi ekspor pertanian diantaranya TFP pertanian (LogTFP), harga dometik pertanian (LogPD), harga ekspor pertanian (LogPX), dan nilai tukar (LogER).

Tabel 3 Hasil uji akar unit terhadap residual persamaan regresi

\begin{tabular}{|c|c|c|c|c|c|}
\hline \multirow[t]{2}{*}{ Variabel } & \multirow[t]{2}{*}{ Nilai ADF } & \multicolumn{2}{|c|}{ Nilai Kritis MacKinnon } & \multirow[t]{2}{*}{ Prob* } & \multirow[t]{2}{*}{ Keterangan } \\
\hline & & $5 \%$ & $10 \%$ & & \\
\hline ECT & -3.641447 & -2.960411 & -2.619160 & 0.0105 & Stasioner \\
\hline
\end{tabular}

Sumber : Data primer, diolah (2013)

Berdasarkan hasil pengujian pada Tabel 3, dapat dilihat bahwa residual dari persamaan regresi stasioner pada tahap level pada selang kepercayaan 5 persen. Hal ini dapat dilihat dari nilai statistik ADF yang lebih kecil dari nilai kritis MacKinnon. Dengan demikian hasil uji stasioneritas terhadap residual semakin menguatkan bahwa diantara variabelvariabel yang digunakan terdapat kointegrasi. Uji kointegrasi dilakukan untuk memperoleh hubungan jangka panjang yang stabil antara variabel-variabel yang terintegrasi pada derajat yang sama.

\section{Pendugaan Model Ekspor Pertanian Jangka Panjang}

Berdasarkan uji kointegrasi yang menunjukkan bahwa terdapat kointegrasi diantara variabel-variabel dalam penelitian, maka model jangka panjang hubungan ekspor pertanian dengan PDB pertanian dan variabel lain yang mempengaruhi ekspor pertanian dapat dilihat pada Tabel 4. Hasil estimasi jangka panjang menunjukkan nilai Adjusted R-squared sebesar 0,82 . Hal ini menunjukkan model jangka panjang hubungan ekspor pertanian dengan PDB pertanian dan variabel lain dapat dijelaskan oleh variabel PDB pertanian, TFP pertanian, harga domestik pertanian, harga ekspor pertanian, dan nilai tukar sebesar 82 persen. Sedangkan sisa nya sebesar 18 persen dijelaskan oleh variabel lain di luar model. Persamaan jangka panjang memiliki probabilitas F-statistik yang lebih kecil dari taraf nyata 5 persen, sehingga seluruh variabel eksogen berpengaruh secara siginifikan terhadap variabel ekspor pertanian secara bersama-sama. 
Berdasarkan model jangka panjang pada Tabel 4 pengujian signifikansi masingmasing variabel eksogen secara statistik diperoleh bahwa variabel PDB pertanian, TFP Pertanian, dan harga domestik pertanian berpengaruh signifikan terhadap ekspor pertanian pada taraf nyata 10 persen. Sedangkan variabel harga ekspor pertanian dan nilai tukar tidak memberikan pengaruh yang signifikan terhadap ekspor pertanian pada taraf nyata 10 persen.

Ekspor pertanian memiliki hubungan jangka panjang dengan PDB pertanian. Hal ini ditunjukkan dari pengaruh signifikan PDB pertanian terhadap ekspor pertanian dalam jangka panjang pada taraf nyata 10 persen. Koefisien PDB pertanian yang bernilai positif menunjukkan bahwa apabila PDB pertanian meningkat sebesar 1 persen maka akan menyebabkan peningkatan ekspor pertanian sebesar 0,76 persen. Koefisien PDB pertanian menunjukkan elastisitas ekspor pertanian terhadap PDB pertanian. Dari hasil estimasi didapat nilai elastisitas kurang dari 1 (satu). Hal ini menunjukkan bahwa ekspor pertanian bersifat inelastis dalam merespon adanya perubahan PDB pertanian.

Tabel 4 Model jangka panjang hubungan ekspor pertanian dengan PDB pertanian dan variabel lain

\begin{tabular}{lcc}
\hline \multicolumn{1}{c}{ Variabel } & Koefisien & Probabilitas \\
\hline $\mathrm{C}$ & 1.997363 & 0.3754 \\
LogPDB & 0.769557 & 0.0938 \\
LogTFP & -0.349958 & 0.0757 \\
LogPD & -0.775984 & 0.0000 \\
LogPX & 0.149411 & 0.1721 \\
LogER & -0.151587 & 0.1151 \\
\hline R-squared & $=0.855246$ & \\
Adjusted R-squared & $=0.827409$ & \\
Prob (F-statistic) & $=0.000000$ & \\
S & & \\
\hline
\end{tabular}

Sumber : Data primer, diolah (2013)

Keterangan : cetak miring menunjukkan stasioner pada tingkat kepercayaan 10 persen.

Penggunaan kemajuan teknologi (TFP) di sektor pertanian memberikan pengaruh yang signifikan terhadap ekspor pertanian dalam jangka panjang pada taraf nyata 10 persen. Koefisien TFP pertanian yang bernilai negatif menunjukkan bahwa apabila TFP pertanian meningkat sebesar 1 persen maka akan menyebabkan penurunan ekspor pertanian sebesar 0,35 persen. Hal ini diduga peningkatan penggunaan kemajuan teknologi di sektor pertanian ditujukan untuk meningkatkan produktivitas produksi dengan orientasi pasar dalam negeri.

Variabel lain yang berpengaruh signifikan pada taraf nyata 10 persen terhadap ekspor pertanian dalam jangka panjang yaitu harga domestik pertanian. Koefisien harga domestik yang bernilai negatif menunjukkan bahwa apabila harga domestik pertanian meningkat sebesar 1 persen maka akan menyebabkan penurunan ekspor pertanian sebesar 0,77 persen. Hubungan koefisien harga domestik pertanian dengan ekspor pertanian dalam jangka panjang bernilai negatif sesuai dengan hasil penelitian Lena (2007). Hasil penelitian menunjukkan bahwa inflasi merupakan faktor dominan yang mempengaruhi ekspor pertanian. Peningkatan inflasi yang mencerminkan kenaikan, menurunkan nilai ekspor karena harga produk pertanian menjadi lebih mahal dan menurunkan daya saing produk pertanian di pasar internasional. Harga yang lebih tinggi menarik minat investor untuk mengurangi volume ekspor karena lebih memilih pasar dalam negeri.

Harga ekspor pertanian dengan nilai tukar diketahui tidak berpengaruh secara signifikan terhadap ekspor pertanian pada taraf nyata 10 persen. Hal ini sesuai dengan hasil penelitian Yudanto (1999) yang menganalisis Dampak Krisis Moneter terhadap Sektor Riil. Penelitian ini melihat seberapa jauh keterkaitan antara fluktuasi nilai tukar terhadap pertumbuhan produksi. Hasil penelitian menunjukkan faktor depresiasi nilai tukar pada krisis moneter memiliki keterkaitan yang erat dengan sektor bangunan, sektor industri dan sektor transportasi. Sedangkan sektor pertanian memiliki korelasi dan elastisitas yang rendah 
terhadap fluktuasi nilai tukar. Hal ini juga ditunjukkan dengan sektor riil yang memiliki basis sumber daya yang kuat, berorientasi ekspor, sumber pembiayaan non rupiah yang rendah serta mempunyai korelasi dan elastisitas yang rendah terhadap perubahan nilai tukar terbukti mampu bertahan dalam krisis bahkan mampu memberikan pertumbuhan secara positif selama krisis. Sektor pertanian merupakan sektor yang mampu bertahan pada saat krisis ekonomi terjadi. Dengan demikian, secara tidak langsung nilai tukar juga tidak memiliki pengaruh yang signifikan terhadap ekspor pertanian, karena tidak memiliki pengaruh yang signifikan terhadap pertumbuhan produksi sektor pertanian.

\section{Pendugaan Model Ekspor Pertanian Jangka Pendek}

ECM digunakan untuk melihat perilaku jangka pendek dari persamaan regresi dengan mengestimasi dinamika Error Correction Term (ECT). Hasil estimasi ECM menunjukkan nilai Adjusted R-Squared sebesar 0,91. Hal ini menunjukkan model hubungan ekspor pertanian dengan PDB pertanian dan variabel lain dalam jangka pendek dijelaskan oleh variabel PDB pertanian, TFP pertanian, harga domestik pertanian, harga ekspor pertanian dan nilai tukar sebesar 91 persen. Sisanya sebesar 9 persen dijelaskan oleh variabel lain di luar model.

Tabel 5 Model jangka pendek hubungan ekspor pertanian dengan PDB pertanian dan variabel lain

\begin{tabular}{cccc}
\hline Variabel & Koefisien & t-statistik & Prob \\
\hline DLOGPDB & -0.751069 & -0.805641 & 0.4310 \\
DLOGPDB(-1) & 1.852740 & 2.051914 & 0.0550 \\
DLOGTFP & -0.184789 & -2.157265 & 0.0447 \\
DLOGTFP(-1) & -0.040702 & -0.359510 & 0.7234 \\
DLOGPX & -0.722227 & -9.352049 & 0.0000 \\
DLOGPX(-1) & 0.061803 & 1.559628 & 0.1363 \\
DLOGPD & 1.112198 & 5.019347 & 0.0001 \\
DLOGPD(-1) & -0.051353 & -0.252420 & 0.8036 \\
DLOGER & -0.047936 & -0.512570 & 0.6145 \\
DLOGER(-1) & -0.126872 & -1.129526 & 0.2735 \\
ECT(-1) & -0.812484 & -4.158089 & 0.0006 \\
\hline
\end{tabular}

Adjusted R-squared $=0.917378$

Sumber : Data primer, diolah (2013)

Keterangan : cetak miring menunjukkan stasioner pada tingkat kepercayaan 10 persen. berikut :

Persamaan Error Correction Model untuk ekspor pertanian yang diperoleh sebagai

$\Delta(\operatorname{LogX}) \quad=-0.751069 \Delta(\operatorname{LogPDB}) \mathrm{t}+1.852740 \Delta(\operatorname{LogPDB}) \mathrm{t}-1-0.184789 \Delta(\log T F P) \mathrm{t}-$

$0.040702 \Delta(\log$ TFP $) \mathrm{t}-1+1.112198 \Delta(\operatorname{LogPD}) \mathrm{t}-0.051353 \Delta(\log P D) \mathrm{t}-1-$

$0.061803 \Delta(\operatorname{LogPX}) \mathrm{t}+0.061803 \Delta(\operatorname{LogPx}) \mathrm{t}-1-0.047936 \Delta(\operatorname{LogER}) \mathrm{t}-$

$0.126872 \Delta(\operatorname{LogER}) \mathrm{t}-1-0.812484(\mathrm{ECT}) \mathrm{t}-1$

Berdasarkan hasil estimasi model jangka pendek diketahui bahwa variabel PDB pertanian satu tahun sebelumnya, TFP Pertanian, harga domestik pertanian dan harga ekspor pertanian berpengaruh signifikan pada ekspor pertanian pada taraf nyata 10 persen. Sedangkan variabel lain tidak berpengaruh signifikan terhadap ekspor pertanian dalam jangka pendek, termasuk nilai tukar. Nilai tukar yang tidak berpengaruh signifikan pada ekspor pertanian sesuai dengan hasil analisis Lena (2007). Berdasarkan analisis faktor-faktor yang mempengaruhi ekspor pertanian dan industri yang dilakukan, didapat bahwa nilai tukar yang menjadi salah satu variabel transmisi kebijakan moneter tidak berpengaruh signifikan 
terhadap ekspor pertanian. Hal ini menunjukkan dalam transmisi moneter melalui nilai tukar tidak bekerja optimal dalam mendorong kinerja sektor pertanian.

PDB pertanian memiliki koefisien yang negatif dalam hubungan jangka pendek terhadap ekspor pertanian. Hal ini menunjukkan bahwa peningkatan PDB pertanian secara langsung dapat menurunkan ekspor pertanian. Peningkatan PDB pertanian tidak berorientasi pada ekspor pertanian, melainkan berorientasi pada pasar domestik. Hal ini dapat dilihat dari rasio ekspor pertanian terhadap PDB pertanian pada Gambar 4.

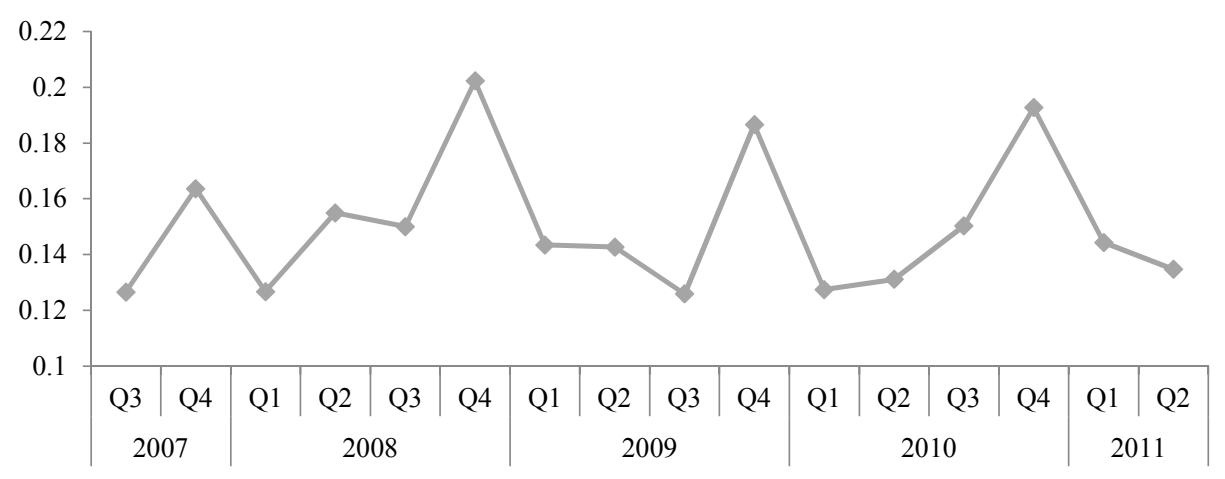

Sumber: CEIC (2012a, 2012e)

Gambar 2 Perkembangan rasio ekspor pertanian-PDB pertanian tahun 2007-2011

Berdasarkan Gambar 2, kontribusi ekspor pertanian terhadap PDB pertanian mengalami fluktuasi dengan nilai yang relatif kecil. Pada triwulan II tahun 2011 rasio ekspor pertanian dengan PDB pertanian sebesar 0.13. Hal ini menunjukkan bahwa hanya 13 persen produk pertanian dengan tujuan pasar ekspor, sedangkan pasar utama produk pertanian adalah pasar domestik. PDB satu tahun sebelumnya memiliki koefisien positif, sehingga memiliki hubungan positif terhadap ekspor pertanian dalam jangka pendek. Hal ini sesuai dengan hipotesis, dengan nilai koefisien sebesar 1,85. Peningkatan PDB pertanian satu tahun sebelumnya secara signifikan sebesar 1 persen menyebabkan peningkatan ekspor pertanian sebesar 1,85 persen. Dengan demikian, dibutuhkan lag waktu satu tahun untuk eskpor pertanian merespon terjadinya perubahan pada PDB pertanian sesuai dengan hipotesis.

Variabel TFP pertanian dan TFP pertanian satu tahun sebelumnya memiliki hubungan negatif terhadap ekspor pertanian dalam jangka pendek. Meskipun TFP pertanian memiliki pengaruh yang signifikan terhadap ekspor pertanian, namun memiliki hubungan negatif. Artinya, peningkatan TFP pertanian sebesar 1 persen makan ekspor pertanian akan mengalami penurunan sebesar 0,18 persen dalam jangka pendek. Sama hal dengan peningkatan PDB pertanian yang memiliki hubungan negatif terhadap ekspor pertanian, peningkatan penggunaan kemajuan teknologi dalam hal ini TFP pertanian akan menyebabkan terjadinya penurunan ekspor pertanian. Hal ini diduga terjadi karena pertumbuhan ekonomi dan penggunaan teknologi di sektor pertanian berorientasi pada peningkatan daya saing produk pertanian dalam negeri untuk jangka pendek.

Variabel lain yang berpengaruh signifikan terhadap ekspor pertanian dalam jangka pendek yaitu harga domestik pertanian dan harga ekspor pertanian. Harga domestik pertanian memberikan pengaruh positif terhadap ekspor pertanian dalam jangka pendek, sedangkan harga ekspor pertanian memberikan pengaruh negatif. Apabila harga domestik pertanian mengalami peningkatan 1 persen maka ekspor pertanian akan meningkat sebesar 1,11 persen. Hal ini menunjukkan peningkatan harga produk pertanian dalam jangka pendek tidak serta merta menarik daya saing produk pertanian dalam negeri dan membuat investor memilih produk pertanian dalam negeri, sehingga dalam jangka pendek peningkatan harga produk pertanian dalam negeri belum bisa mengurangi jumlah ekspor pertanian. Sedangkan pengaruh variabel harga ekspor pertanian menunjukkan apabila harga ekspor pertanian 
mengalami peningkatan sebesar 1 persen, maka secara langsung mengakibatkan ekspor pertanian turun sebesar 0,72 persen. Sama hal dengan harga pertanian dalam negeri, peningkatan harga ekspor pertanian tidak serta-merta menarik peningkatan jumlah ekspor pertanian, tetapi membutuhkan penyesuaian dalam beberapa periode selanjutnya.

Tanda parameter yang sesuai dengan hipotesis untuk harga domestik pertanian dan harga ekspor pertanian terjadi pada variabel harga domestik satu tahun sebelumnya dan harga ekspor pertanian satu tahun sebelumnya. Peningkatan harga domestik satu tahun sebelumnya dapat menyebabkan ekspor pertanian menurun karena harga domestik yang tinggi menyebabkan penawaran produk pertanian di pasar domestik meningkat. Dengan demikian, harga ekspor pertanian yang tinggi akan menstimulasi peningkatan penawaran produk pertanian Indonesia di pasar internasional. Nilai koefisien Error Correction Term (ECT) sebesar -0,81 menunjukkan bahwa variabel yang digunakan memiliki kointegrasi dan bisa menjelaskan hubungan kausalitas dari variabel-variabel yang diuji baik jangka pendek maupun jangka panjang.

\section{Perubahan Struktur (Structural Change) Pada Model Ekspor Pertanian}

Pengujian structural change dapat dilakukan melalui uji stabilitas pada persamaan ECM ekspor pertanian yang sudah dilakukan sebelumnya. Pengujian ini dilakukan untuk melihat apakah adanya perubahan struktural (structural change) pada persamaan ECM pada satu waktu tertentu, dalam hal ini akibat adanya krisis ekonomi yang terjadi di Indonesia pada tahun 1997.

Tabel 6 Chow forecast test dengan breakpoints tahun 1997

\begin{tabular}{|c|c|c|}
\hline F-statistik & $=1.886768$ & Probability $=0.2243$ \\
\hline Log likelihood ratio & $=46.89263$ & Probability $=0.0000$ \\
\hline
\end{tabular}

Sumber : Data primer, diolah (2013)

Berdasarkan Tabel 6 diketahui bahwa $p$-value dari Log likelihood ratio lebih kecil dari taraf nyata 10 persen. Hal ini menunjukkan bahwa terdapat structural change pada persamaan ECM ekspor pertanian pada tahun 1997. Dengan demikian, selama periode penelitian, 1980 sampai dengan 2011, terdapat perubahan struktur (structural change) ekonomi pada parameter-parameter yang digunakan. Perubahan pada parameter-parameter pada model dapat memberikan pengaruh yang berbeda. Dengan demikian, hasil pengujian structural change akan dilanjutkan pada penambahan variabel dummy krisis ekonomi pada persamaan jangka pendek hubungan ekspor pertanian dengan PDB pertanian dan variabel lain yang mempengaruhi ekspor pertanian. Dummy krisis ekonomi digunakan dengan memberi nilai 0 pada periode sebelum dan setelah krisis ekonomi ( 1980-1996) dan (19982011) serta memberi nilai 1 pada periode selama krisis ekonomi (1997). Hasil estimasi persamaan yang baru dapat dilihat pada Tabel 7 .

Hasil estimasi model ECM yang baru menunjukkan nilai Adjusted R-squared sebesar 0,92. Hal ini menunjukkan model jangka pendek hubungan ekspor pertanian dengan PDB pertanian dan variabel lain dapat dijelaskan oleh variabel PDB pertanian, TFP pertanian, harga domestik pertanian, harga ekspor pertanian, nilai tukar dan dummy krisis ekonomi sebesar 92 persen. Sedangkan sisanya sebesar 8 persen dijelaskan oleh variabel lain di luar model. Persamaan jangka pendek yang baru memiliki probabilitas F-statistik yang lebih kecil dari taraf nyata 10 persen, sehingga seluruh variabel eksogen berpengaruh secara siginifikan terhadap variabel ekspor pertanian secara bersama-sama.

Persamaan Error Correction Model untuk ekspor pertanian yang baru, sebagai berikut :

$\Delta(\operatorname{LogX})=-1.007056 \Delta(\operatorname{LogPDB}) \mathrm{t}+2.035402 \Delta(\operatorname{LogPDB}) \mathrm{t}-1-0.222089 \Delta(\log T \mathrm{PF}) \mathrm{t}$ $+0.0000835 \Delta(\operatorname{LogTFP}) \mathrm{t}-1+1.204006 \Delta(\operatorname{LogPD}) \mathrm{t}-0.081715 \Delta(\operatorname{LogPD}) \mathrm{t}-1$

$-0.724870 \Delta(\operatorname{LogPX}) \mathrm{t}+0.065066 \Delta(\operatorname{LogPx}) \mathrm{t}-1-0.205856 \Delta(\operatorname{LogER}) \mathrm{t}-$ $0.099531 \Delta(\operatorname{LogER}) t-1+0.076897$ DummyKR -0.854797 (ECT)t-1. 
Berdasarkan model jangka pendek yang baru, pengujian signifikansi masing-masing variabel eksogen secara statistik diperoleh bahwa variabel PDB pertanian satu tahun sebelumnya, TFP Pertanian, harga domestik pertanian, harga ekspor pertanian, harga ekspor pertanian satu tahun sebelumnya, dan dummy krisis ekonomi tahun 1997 berpengaruh signifikan terhadap ekspor pertanian pada taraf nyata 10 persen. Dengan demikian, dapat dilihat adanya perubahan terhadap parameter variabel-variabel yang digunakan setelah ditambahkan variabel dummy krisis moneter.

Tabel 7 Model jangka pendek hubungan ekspor pertanian dengan PDB pertanian dan variabel lain yang baru

\begin{tabular}{cccc}
\hline Variabel & Koefisien & t-statistik & Probabilitas \\
\hline DLOGPDB & -1.007056 & -1.126204 & 0.2757 \\
DLOGPDB(-1) & 2.035402 & 2.364501 & 0.0302 \\
DLOGTFP & -0.222089 & -2.650450 & 0.0168 \\
DLOGTFP(-1) & $8.35 \mathrm{E}-05$ & 0.000762 & 0.9994 \\
DLOGPX & -0.724870 & -9.915782 & 0.0000 \\
DLOGPX(-1) & 0.065066 & 1.732867 & 0.1012 \\
DLOGPD & 1.204006 & 5.571582 & 0.0000 \\
DLOGPD(-1) & -0.081715 & -0.422711 & 0.6778 \\
DLOGER & -0.205856 & -1.633209 & 0.1208 \\
DLOGER(-1) & -0.099531 & -0.926455 & 0.3672 \\
DummyKR & 0.076897 & 1.759727 & 0.0964 \\
ECT(-1) & -0.854797 & -4.583811 & 0.0003 \\
\hline Adjusted R-squared & $=0.925998$ & &
\end{tabular}

Sumber : Data primer, diolah (2013)

Keterangan : cetak miring menunjukkan stasioner pada tingkat kepercayaan 10 persen.

Dalam jangka pendek, PDB pertanian tetap memiliki tanda koefisien parameter yang negatif terhadap ekspor pertanian, dikarenakan pasar utama produk pertanian bukan ekspor melainkan pasar dalam negeri. PDB pertanian satu tahun sebelumnya yang memiliki tanda koefisien positif, sesuai hipotesis, menunjukkan peningkatan 1 persen PDB pertanian akan meningkatkan ekspor pertanian sebesar 2,03 persen. Nilai ini menunjukkan elastisitas pengaruh PDB pertanian terhadap ekspor pertanian lebih elastis dibandingkan dengan hasil sebelum adanya variabel dummy krisis moneter.

Sama hal dengan PDB pertanian, TFP pertanian juga tetap memberikan pengaruh negatif terhadap ekspor pertanian dalam jangka pendek. Apabila TFP pertanian meningkat 1 persen maka ekspor pertanian akan turun sebesar 0,22 persen. Seperti telah disebutkan sebelumnya, peningkatan pertumbuhan ekonomi serta peningkatan penggunaan kemajuan teknologi tidak langsung berpengaruh positif terhadap peningkatan ekspor pertanian. Diduga terjadi karena pertumbuhan ekonomi dan penggunaan teknologi di sektor pertanian berorientasi pada peningkatan daya saing produk pertanian dalam negeri untuk jangka pendek. Sedangkan TFP pertanian satu tahun sebelumnya memberikan pengaruh positif terhadap ekspor pertanian. Hal ini memperlihatkan adanya penyesuaian respon ekspor pertanian terhadap kemajuan teknologi di sektor pertanian pada lag waktu satu tahun.

Harga ekspor pertanian yang meningkat sebesar 1 persen akan menyebabkan penurunan ekspor pertanian sebesar 0,72 persen. Hal ini tidak sesuai dengan hipotesis, jika terjadi peningkatan harga pada ekspor produk pertanian maka akan menstimulasi para investor untuk meningkatkan ekspor produk pertanian di pasar internasional. Kondisi ini masih sama dengan hasil estimasi pada model ECM sebelum terdapat dummy krisis ekonomi, bahwa peningkatan harga ekspor pertanian tidak langsung direspon positif oleh peningkatan jumlah ekspor pertanian melainkan adanya penyesuaian pada beberapa lag 
waktu. Tanda koefisien parameter yang sesuai hipotesis ditunjukkan oleh hubungan harga ekspor pertanian satu tahun sebelumnya terhadap ekspor pertanian, yaitu positif sebesar 0,06 . Nilai ini menunjukkan peningkatan 1 persen harga ekspor pertanian satu tahun sebelumnya, akan meningkatkan ekspor pertanian.

Variabel lain yang berpengaruh signifikan terhadap ekspor pertanian dalam jangka pendek yaitu harga domestik pertanian. Harga domestik pertanian memberikan pengaruh positif terhadap ekspor pertanian dalam jangka pendek. Apabila harga domestik pertanian mengalami peningkatan 1 persen maka ekspor pertanian akan meningkat sebesar 1,20 persen. Kondisi ini masih sama seperti hasil estimasi sebelum adanya dummy krisis ekonomi, bahwa peningkatan harga produk pertanian tidak serta merta menarik daya saing produk pertanian dalam negeri dan membuat investor memilih produk pertanian dalam negeri, sehingga dalam jangka pendek peningkatan harga produk pertanian dalam negeri belum bisa mengurangi jumlah ekspor pertanian.

Berbeda dengan harga domestik pertanian, harga domestik pertanian satu tahun sebelumnya berpengaruh negatif terhadap ekspor pertanian. Apabila harga domestik pertanian tahun sebelumnya mengalami peningkatan 1 persen, maka ekspor pertanian akan mengalami penurunan 0,08 persen. Kondisi ini menunjukkan bahwa respon perubahan ekspor pertanian terhadap harga domestik yang sesuai dengan hipotesis memiliki lag waktu satu tahun.

Sedangkan nilai tukar maupun nilai tukar satu tahun sebelumnya berpengaruh negatif terhadap ekspor pertanian. Tanda koefisien parameter yang negatif ini juga disertai dengan tidak adanya pengaruh signifikan baik nilai tukar maupun nilai tukar sebelumnya terhadap ekspor pertanian. Ekspor pertanian lebih dipengaruhi oleh harga pasar internasional, dalam hal penelitian ini variabel harga ekspor pertanian dan harga ekspor pertanian satu tahun sebelumnya. Hal ini didukung oleh hasil penelitian Pratika (2007) yang melakukan analisis hubungan nilai tukar terhadap ekspor komoditi unggulan pertanian bahwa fluktuasi nilai tukar tidak memiliki pengaruh terhadap nilai ekspor karet dan kopi. Begitu pula dengan hasil penelitian Ambarinanti (2007) yang menunjukkan bahwa nilai tukar tidak berpengaruh signifikan terhadap ekspor beras Indonesia.

Berdasarkan hasil analisis jangka pendek yang baru, setelah ditambahkan variabel dummy krisis moneter, dapat kita lihat bahwa PDB pertanian satu tahun sebelumnya, TFP pertanian satu tahun sebelumnya, harga domestik satu tahun sebelumnya dan harga ekspor pertanian satu tahun sebelumnya memiliki tanda koefisien parameter yang sesuai dengan hipotesis. Hal ini menunjukkan terdapat time lag ekspor pertanian dalam merespon variabelvariabel yang mempengaruhinya. Nilai koefisien Error Correction Term (ECT) sebesar 0,85 menunjukkan bahwa variabel yang digunakan memiliki kointegrasi dan bisa menjelaskan hubungan kausalitas dari variabel-variabel yang diuji baik jangka pendek maupun jangka panjang.

\section{KESIMPULAN DAN SARAN}

\section{Kesimpulan}

Kesimpulan dari hasil penelitian, sebagai berikut :

1. Dalam jangka panjang, PDB pertanian (+), TFP Pertanian (-), dan harga domestik pertanian (-) berpengaruh signifikan terhadap ekspor pertanian. Sedangkan variabel harga ekspor pertanian dan nilai tukar tidak memberikan pengaruh yang signifikan terhadap ekspor pertanian. Tanda koefisien TFP pertanian tidak sesuai dengan hipotesis diduga karena penggunaan kemajuan teknologi di sektor pertanian ditujukan untuk meningkatkan produktivitas produksi dengan orientasi pasar dalam negeri.

2. Berdasarkan hasil estimasi ECM, variabel-variabel yang berpengaruh langsung (jangka pendek) secara signifikan terhadap ekspor pertanian di Indonesia diantaranya PDB 
pertanian satu tahun sebelumnya $(+)$, TFP Pertanian $(-)$, harga domestik pertanian $(+)$ dan harga ekspor pertanian (-).

3. Analisis structural change menunjukkan bahwa terdapat perubahan struktur pada model ECM di tahun 1997. Hasil estimasi ECM dengan ditambahkan dummy krisis ekonomi tahun 1997 menunjukkan bahwa variabel PDB pertanian satu tahun sebelumnya $(+)$, TFP Pertanian (-), harga domestik pertanian (+), harga ekspor pertanian $(-)$, harga domestik pertanian satu tahun sebelumnya $(+)$, dan dummy krisis ekonomi tahun 1997 $(+)$ berpengaruh signifikan terhadap ekspor pertanian.

4. Hasil analisis ECM yang baru menunjukkan tanda koefisien parameter variabel PDB pertanian, TFP pertanian, harga domestik pertanian, harga ekspor pertanian, yang sesuai hipotesis adalah variabel dengan lag satu tahun. Artinya, terdapat time lag ekspor pertanian dalam merespon variabel yang mempengaruhinya.

\section{Saran}

Saran kebijakan berdasarkan hasil penelitian, sebagai berikut :

1. Mengembangkan pasar ekspor pertanian yang sudah ada. Mengorientasikan produksi komoditi-komoditi di sektor pertanian bukan hanya untuk pasar dalam negeri, akan tetapi juga ekspor produk pertanian. Mengingat sektor pertanian berpotensi sebagai sumber devisa negara.

2. Memperhatikan kondisi ekonomi yang dapat menyebabkan structural change, karena structural change yang terjadi dapat berpengaruh terhadap variabel-variabel ekonomi.

\section{DAFTAR PUSTAKA}

Abdullah, Ahmad Zainuddin. 1993. Export-Led Growth in Malaysia Agriculture : A VAR Approach. Pertanika J.Soc. Sci.\& Hum. 1(1):63-69.

Aliman, Purnomo AB. 2001. Kausalitas Antara Ekspor dan Pertumbuhan Ekonomi. Jurnal Ekonomi dan Bisnis Indonesia. 16(2):122-137.

[CEIC] CEIC Data Company Ltd. 2012a. Produk Domestik Bruto (PDB) Berdasarkan Lapangan Usaha. Jakarta (ID): Badan Pusat Statistik (BPS).

[CEIC] CEIC Data Company Ltd. 2012b. Realisasi Investasi Dalam Negeri (PMDN) Berdasarkan Lapangan Usaha. Jakarta (ID): Badan Koordinasi Penanaman Modal (BPKM).

[CEIC] CEIC Data Company Ltd. 2012c. Realisasi Investasi Asing (PMA) Berdasarkan Lapangan Usaha. Jakarta (ID): Badan Koordinasi Penanaman Modal (BKPM).

[CEIC] CEIC Data Company Ltd. 2012d. Tenaga Kerja Berdasarkan Lapangan Usaha. Jakarta (ID): Badan Pusat Statistik (BPS).

[CEIC] CEIC Data Company Ltd. 2012e. Ekspor Berdasarkan Komoditas Utama. Jakarta (ID): Badan Pusat Statistik (BPS).

Dedy M. 2010. Peran Sektor Pertanian Dalam Pertumbuhan Ekonomi di Indonesia [Tesis]. Bogor (ID): Institut Pertanian Bogor.

Dornbusch R. 2008. Macroeconomics. New York (AS): McGraw-Hill.

Enders W. 1995. Applied Econometric Time Series. New York (AS): John Wiley \& Sons, Inc.

Engle RF, Granger CWJ. 1987. Co-integration and Error Correction : Representation, Estimation, and Testing. Econometrica. 55(2): 251-276.

Gujarati D. 1978. Ekonometrika Dasar. Sumarno Zain, penerjemah. Jakarta (ID): Penerbit Erlangga.

Isdijoso B. 1992. Model Ekonomi Makro Dan Keterkaitan Sektor Pertanian Di Indonesia [Tesis]. Bogor (ID): Institut Pertanian Bogor.

Kuznets S. 1971. Economic Growth of Nations. Cambridge (AS): Harvard University Press. 
Nkang N.M. 2006. Co-integration and Error-Correction Modelling of Agricultural Export Trade in Nigeria : The Case of Cocoa. Journal of Agriculture \& Social Sciences. Vol 2(4): $1-14$

Oskoee MB. 2005. Export Led Growth Hypothesis Revisited: A Panel Cointegration Approach. Scientific Journal of Administrative Development. Vol 3 I.A.D: 8798.

Pahlavani M. 2005. Cointegration and Structural Change In The Exports - GDP Nexus : The Case of Iran. International Journal of Applied Econometrics and Quantitative Studies. Vol.2(4): 1-20.

Waheed M. 2007. Structural Breaks and Unit Root: Evidence from Pakistani Macroeconomic Time Series. MPRA Paper. Vol 1797(07): 1-20. 